The descriptions are good, and the book avoids the excessive Americanisms which are so irritating and puzzling to those who have not lived in the United States. The care with which the book has been compiled makes it a pleasure to look up a fact, and the reader can be sure of finding the latest information on almost any psychiatric subject.

ClIFFORd Allen

\section{ESSENTIAL OILS OF THE CITRUS AND MINT FAMILIES}

The Essential Oils

By Dr. Ernest Guenther. Vol. 3 : Individual Essential Oils of the Plant Families Rutaceae and Labiatae. Pp. xvi + 777. (New York: D. Van Nostrand Co., Inc.; London: Macmillan and Co., Ltd., 1949.) 75s. net.

TN this third volume Dr. Ernest Guenther begins to speak of trees, though, inverting Solomon's order, he has placed the hyssop near the beginning of his discourse and reserved the cedar, no doubt, for later treatment. The order chosen is, in fact, that of commercial importance, giving priority accordingly to the two botanical families which include peppermint, lavender and the citrus group.

The alternative of classification on a taxonomic botanical basis may well have appeared a tempting one. A phylogeny of plants in terms of their chemical components, elegantly illustrating the achievements of the morphologist and resolving his dilemmas, seems one of the most attractive prospects which chemistry may still have to offer. Bold spirits, quoted in Dr. Guenther's first volume, have already "distinguished species indistinguishable by ordinary morphological techniques, on the basis of the production of oils of different chemical composition". A more modest example from the present volume, namely, Fujita's chemical demonstration of the interrelations of fifteen species of the tangled labiate genus Orthodon, may be mentioned as noteworthy, inasmuch as Fujita's work is not otherwise easily accessible.

On the other side, the present volume cites cases of distinctly different oils being produced in identical conditions by trees showing, at most, the differences of horticultural strains of one and the same variety. Throughout the book, moreover, there is ample evidence of the dependence of essential-oil composition on the phase of maturity of the plant, and on geographical, ecological and less tangible factors, some of which are further detailed below. If a taxonomy by essential-oil content is ever to be constructed, Dr. Guenther's work will provide a rich quarry of the necessary material, and the "table or key showing the classification of the oils according to a modern botanical system", envisaged as an item in his final volume, must be awaited with interest. For the present, however, the choice of a perspective which relegates this mistier outline to the background seems well advised.

These volumes may therefore be taken as primarily for the benefit of essential-oil producers and consumers and the analysts who advise them. There is much wisdom in the warning that "the two points of view-one aimed at finding out what is wrong with the oil, and the other at trying to define the facts relative to pure oils-not infrequently lead to different conclusions". In effect, it is to the convenience of the consumer to define the authenticity of any oil by analytical criteria as sharp and narrow as possible; but with this ambition the enterprise of the producer, complementing that of Nature, is continually in conflict.

Within the past decade, large-scale essential-oil industries have been developed in areas more or less remote from the original homes of the plants concerned. The Argentine is now a large producer of peppermint oil, Brazil of the menthol-rich oil of corn-mint. In the U.S.S.R., though information from there is found confused and contradictory, at least the foundations of a large lavender industry appear to have been laid (it is of interest to note that, in comparing the oil yields of more than nine hundred strains, a count of the oil-sacs on only five sepals is said to give a satisfactory assessment of the productivity of any one strain). Change of habitat on this scale must always be a probable source of change in the characters of the relevant oil. Of this there is a striking example in the mandarin and tangerine oranges, which for oil-producing purposes in the eastern hemisphere have usually been considered synonymous, but which in Brazil yield oils of decidedly different character, while in North America the oil is wholly of the type 'tangerine', with optical rotation much higher than in any mandarin oil. (The American idiom which distinguishes these oranges with flexible and smoothly peeling skin as the 'kidglove' type is one at which. it is surely proper to pause and admire.)

To variations of this kind must now be added those which are beginning to be produced by artificial genetic modifications, for example, in the tetraploid peppermints recently obtained at Purdue University by colchicine treatment, and the artificial hybrids, said to contain oil-constituents not present in the parents, bred by Russian workers from species of Ocimum. Notice should also be taken of variations in oil character correlating with changes in extraction technique, especially in the citrus fruits. A much increased demand for citrus juices fitted for beverage purposes, coinciding over recent years with a declining importance of citrus pulps, compared with the fermentation-vat, as a source of citric acid, may involve changes in processing quite sufficient to modify the analytical character of the oil, and to raise a doubt of its authenticity if judged by any too dogmatic criterion. Through these pitfalls for the authenticating analyst, Dr. Guenther must prove an invaluable guide. In at least one matter of nomenclature, also, he is consistent in a usage which might avoid no little confusion if generally adopted, namely, the treatment of the descriptions "neroli" and "petitgrain" purely as adjectives, respectively equivalent to "distilled from flowers" and "distilled from shoots" and meaningless in themselves until the name of the tree concerned is added.

In its detailed structure, the book is a series of monographs on all the recognized varieties of the oils within its scope, covering history, production technique and statistics, analytical characters and as much detail of chemical composition as is available. With the examples of the first two volumes before us (see Nature, 163, 663; 1949 and 164,$895 ; 1949$ ) it is scarcely necessary to say that it is excellently produced and indexed; though it may be observed that, in both index and text, hesperetin is misprinted in a form, hesperitin, which could confuse it with hesperidin.
E. G. KELLETT 